\title{
Evaluation of Growth and Nutritional Status of Preschool Children: a Pilot Study in the Cold Area of China
}

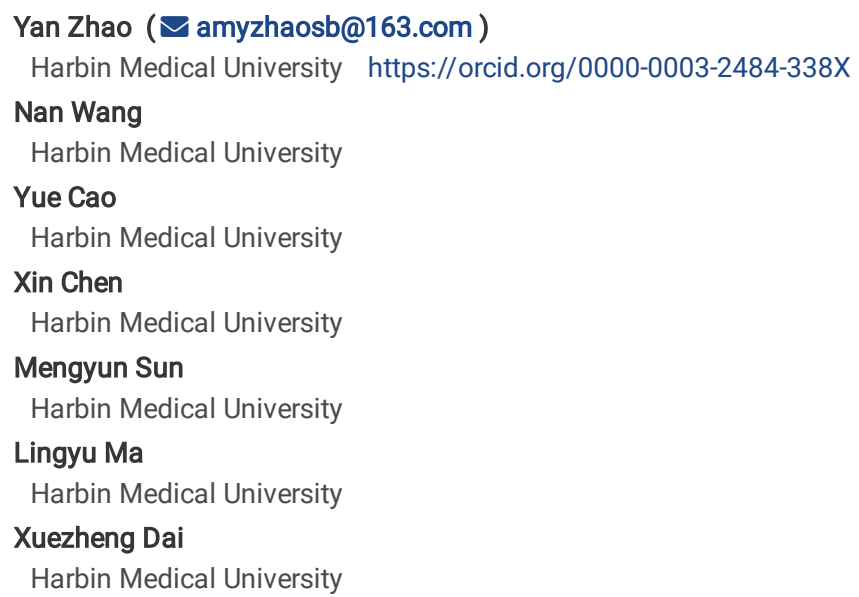




\section{Abstract}

\section{Background}

The growth and development of children is influenced not only by heredity but also by environmental factors, including nutrition and temperature. The aim of this study was to evaluate the growth and nutritional status of preschool children in Daxing'anling, the coldest region of China.

\section{Methods}

A descriptive, cross-sectional survey was performed among preschool children aged 3 to 6 years by stratified cluster sampling in Daxing'anling. The children's parents completed the questionnaires. Height, body weight and head circumference were measured, and Z scores for weight for height, weight for age, height for age and head circumference for age were evaluated. Anthropometric data were compared with World Health Organization standards and China's growth references. The levels of vitamin $A, E$ and $25-(\mathrm{OH})-\mathrm{D}_{3}$ in serum were detected by high-performance liquid chromatography.

\section{Results}

A total of 305 children were recruited. The average height of the preschool children was lower than China's growth reference but higher than the WHO standard. More than half of the preschool children ranged from -1 SD to +1 SD. Both the values of weight for height and of weight for age were positive and higher than the WHO standards $(P<0.01)$, with a significant difference between boys and girls $(P<0.01)$. The incidence of stunting, wasting, and underweight were $4.59 \%, 2.95 \%$ and $2.30 \%$, respectively, although the prevalence of overweight and obesity was high ( $18.03 \%$ and $6.89 \%$, respectively). The rates of vitamin $A$ and $D$ deficiency were $7.54 \%$ and $88.85 \%$, respectively. Vitamin A was also positively associated with $25-(\mathrm{OH})-\mathrm{D}_{3}$.

\section{Conclusions}

The growth and nutritional status of preschool children were generally good, although the double burden of malnutrition was observed. Vitamin D deficiency should be paid much attention to. It is necessary and urgent to carry out nutritional interventions for health.

\section{Background}

Nutrition has a profound influence on health over a lifetime. The Lancet series on maternal and child malnutrition in 2008 and 2013 illustrated the potential consequences of malnutrition on health[1-3]. In recent years, the rates of stunting, underweight and wasting in children have gradually decreased, whereas increasing trends in child overweight and obesity are occurring in most world regions. Globally, stunting among children under five years of age has fallen from 198.4 million (32.6\%) in 2000 to 150.8 million (22.2\%) in 2017, while 50.5 and 38.3 million children are wasted and overweight, respectively. Therefore, malnutrition is a universal issue worldwide. Preschool children aged three to six years in particular require focused attention because this age group not only has special needs but also forms the platform for the growth and development of children[4]. It was found that the most important determinant of the growth and development of children was not heredity or race but the influence of nutrition and environment[5]. Therefore, children's nutritional status is a sensitive indicator for children's health levels.

$Z$ scores are usually used to evaluate growth and nutritional status of children. The results are objective and credible by excluding the effects of sex, age and weight. The Z scores of each child were calculated for weight for height (WHZ), weight for age (WAZ), height for age (HAZ) and head circumference for age (HCZ) 6,7$]$. The current China growth reference was established based on a nine-city study in 2005. The nine cities, including Beijing, Harbin, Xi'an, Shanghai, Nanjing, Wuhan, Fuzhou, Guangzhou and Kunming, are located in North, Central and South China. The results showed that the growth and development levels of children in China exceeded the WHO standard for children of the same age[8]. Data from the China National Nutrition and Health Survey (CNNHS) in 2002 showed that the prevalence of undernutrition was high, but the prevalence of overweight was lower than WHO standards[9].

Underweight, wasting and stunting are still common in children worldwide, but overweight and obesity are increasing at an alarming speed. The prevalence of underweight, overweight and obesity was $13 \%, 18 \%$ and $16 \%$, respectively, in 754 preschool children in Tbilisi[10]. Among children under five years old in the West Azerbaijan Province in Iran, the prevalence of stunting, overweight and obesity were $7.3 \%, 1.3 \%$ and $5.1 \%$, respectively[11]. The global prevalence of preschool overweight plus obesity increased from $4.2 \%$ in 1990 to $6.7 \%$ in 2010 , with a projected increase to $9.1 \%$ in 2020[12]. The proportion of children with overnutrition increases about the same year by year in China[13-16]. In a 2013 survey, the prevalence of overweight and obesity in Chinese children under 6 years old was $8.4 \%$ and $3.1 \%$, respectively, and increased by 1.9 and 0.4 percentage points from 2002[17]. The overall prevalence of wasting and underweight Chinese children under 6 years was $2.0 \%$ and $2.5 \%$, respectively, in the 2013 survey, and the rate of underweight decreased by 3.2 percentage points[17]. Although the nutritional status of children has been greatly improved in China, a lack of vitamins and other micronutrients is still prominent and is urgently to be solved.

In addition to genetic factors, children's nutritional status is also influenced by environmental factors. Cold weather has a wide range of impacts on children's growth and health[18, 19]. It was reported that cold temperatures affected children aged 6 to 24 months[20], but the influence of extremely cold temperature on older children's growth and nutritional status is still unclear. Daxing'anling is the northernmost and coldest region of China. The annual average temperature is $-2.6^{\circ} \mathrm{C}$, and the extreme minimum temperature can reach $-52.3^{\circ} \mathrm{C}$. It is known as an alpine restricted zone. Therefore, the current study aimed to investigate the growth and nutritional status of preschool children in Daxing'anling.

\section{Methods}


A descriptive cross-sectional survey of preschool children aged 3 to 6 years old from four kindergartens in Daxing'anling in 2015 according to the geographical location and economic levels was performed. The economic conditions of the children's families can reflect the region's average levels. Demographic information included children's name, sex, age and birth weight. Children with incomplete information were excluded. A total of 305 children were finally recruited. Harbin Medical University approved the study protocol, and informed written consent was obtained from the children's parents/guardians. All study procedures were carried out following the Helsinki Declaration[21].

\section{Anthropometric measurements}

The children's height, weight and head circumference were measured in light clothing while barefoot and without hats according to WHO standard procedures[22].

WHO AnthroPlus software (2009) was used to calculate individual HAZ, WAZ, HCZ and WHZ. Z scores were the ratio of the difference between the observed value and the mean plus standard deviation of the reference population[23]. According to the $Z$ scores, the growth and development of children were divided into 5 different levels: a cut-off less than minus two standard deviations (-2 SD) was defined as Z1, between -2 SD and -1 SD as Z2, between -1 SD to +1 SD as Z3, between +1 SD and +2 SD as Z4, and more than +2 SD as Z5.

\section{Evaluation criteria of nutritional status}

Stunting, underweight, wasting and a small head circumference were defined when the values of HAZ, WAZ, WHZ and HCZ were less than - 2 SD. Similarly, overweight and large head circumference were defined when the values of WHZ and HCZ were more than + 2 SD, obesity was defined when the values of WHZ was more than $+3 \mathrm{SD}$ [12]. The standards were divided into four indicator categories: three negative, single positive, two positive and three positive.

Furthermore, according to the demographic information from birth certificates, the birth weight of preschool children was considered low when the weight was less than $2.5 \mathrm{~kg}$, normal when the weight was between 2.5 to $4.0 \mathrm{~kg}$ and high when the weight was more than $4.0 \mathrm{~kg}$.

\section{Assessment of vitamin levels}

Two millilitres of venous blood was collected and centrifuged and serum was separated and stored at $-80^{\circ} \mathrm{C}$. High-performance liquid chromatography (HPLC) was used to detect the contents of vitamin $A, 25-(\mathrm{OH})-\mathrm{D}_{3}$ and vitamin $\mathrm{E}$ in serum. Briefly, blood samples were extracted with hexane after deproteinization with ethanol and then evaporated to dry with nitrogen gas. The residue was dissolved in $0.1 \mathrm{ml}$ methanol. Twenty microliters of the sample was injected into a C18 column installed with an HPLC apparatus (Waters 2695 Quarternary HPLC Pump, Waters 2487, USA). All procedures were performed in a dark room to protect the serum from light. The mobile phase was a methanol-deionized water mixture (97:3). The concentrations of vitamin $A, 25-(O H)-D_{3}$ and vitamin $E$ were determined by spectrophotometry (Waters 2487 Dual y Absorbance Detector, USA) at 315, 265 and 290 nm, respectively.

According to the diagnostic criteria recommended by the WHO, a content of serum vitamin A higher than $0.3 \mu \mathrm{g} / \mathrm{ml}$ was defined as normal, from 0.2 to 0.3 $\mu \mathrm{g} / \mathrm{ml}$ as marginal vitamin A deficiency, and lower than $0.2 \mu \mathrm{g} / \mathrm{ml}$ as vitamin A deficiency (including subclinical and clinical vitamin A deficiency). The vitamin E content in serum ranged from 5 to $20 \mu \mathrm{g} / \mathrm{ml}$ and was normal, with less than $5 \mu \mathrm{g} / \mathrm{ml}$ considered vitamin $E$ deficiency. The content of serum $25-(\mathrm{OH})-\mathrm{D}_{3}$ lower than $20 \mathrm{ng} / \mathrm{ml}$ was considered vitamin D deficiency, between $20 \mathrm{ng} / \mathrm{ml}$ and $30 \mathrm{ng} / \mathrm{ml}$ as insufficient, and between $30 \mathrm{ng} / \mathrm{ml}$ and $100 \mathrm{ng} / \mathrm{ml}$ as sufficient; content higher than $150 \mathrm{ng} / \mathrm{ml}$ could signal vitamin D poisoning[24-27].

\section{Statistical analyses}

All statistical analyses were performed using SPSS 20.0 software. WHO (Anthroplus) software was used to calculate Z scores. Comparisons of the differences among continuous variables were performed using a t test or one-way analysis of variance. Categorical variables were analysed using the chi-squared test and Fisher's exact test. The correlation of individual vitamins was estimated by Pearson's or Spearman's correlation. Statistical significance was accepted at a $P$ value less than 0.05 .

\section{Results}

\section{Physical development}

Among preschool children aged three to six years in Daxing'anling, boys aged five and six years had taller heights, and the weights and head circumferences of boys aged five years were significantly greater than those of girls of the same age $(P<0.05)$. Compared with the China growth reference for the same sex and age, the height of preschool children in Daxing'anling was lower, except for boys aged 6 years $(P<0.05)$. However, there was no significant difference in weight and head circumference (Fig. 1a).

\section{Assessment of growth and development}

The mean values of WHZ, WAZ, HAZ, and HCZ (SD) were 0.83 (1.52), 0.58 (1.21), 0.05 (1.23), and 0.05 (1.11), respectively. Both WHZ and WAZ values were positive and higher than the WHO standards $(\mathrm{P}<0.01)$. WHZ decreased with age, while the values of HAZ at 3,4 and 6 years and HCZ at 3 years were negative (Fig. 1b). The WHZ and WAZ values of boys were significantly higher than those of girls $(P<0.01)$. However, there was no significant difference in HAZ and HCZ between boys and girls (Fig. 1c). The levels of WAZ were between -1 SD and +2 SD (Z3 and Z4) in $86.6 \%$ of children, followed by more than +2 SD (Z5) in $8.2 \%$ of children (Table 1). The changes in WHZ had a similar tendency as WAZ. However, the levels of HAZ were between - 1 SD and +1 SD (Z3) in $63.6 \%$ of children, followed by levels between +1 SD and +2 SD (Z4) as well as between -2 SD and - 1 SD (Z2). Large and small head circumference included 11 and 10 children, respectively. More than $90 \%$ of children had normal head circumferences. 
Table 1

The distribution of WAZ, WHZ and HAZ scores among preschool children

\begin{tabular}{|c|c|c|c|c|c|c|c|c|c|c|c|c|c|c|c|c|c|}
\hline \multirow[t]{2}{*}{ Sex } & \multirow[t]{2}{*}{ Age } & \multirow[t]{2}{*}{$\mathrm{n}$} & \multicolumn{3}{|l|}{$\mathrm{Z1}(\%)$} & \multicolumn{3}{|c|}{$\mathrm{Z2}(\%)$} & \multicolumn{3}{|l|}{ Z3(\%) } & \multicolumn{3}{|l|}{ Z4(\%) } & \multicolumn{3}{|l|}{$\mathrm{Z5}(\%)$} \\
\hline & & & WAZ & WHZ & $H A Z^{a}$ & WAZ & WHZ & HAZ & WAZ & WHZ & HAZ & WAZ & WHZ & HAZ & $W A Z^{b}$ & $\mathrm{WHZ}^{\mathrm{c}}$ & HAZ \\
\hline \multirow[t]{4}{*}{ Boys } & $3 \rrbracket$ & 48 & 6.25 & 4.17 & 2.08 & 2.08 & 2.08 & 10.42 & 54.17 & 39.58 & 68.75 & 27.08 & 31.25 & 18.75 & 10.42 & 22.92 & 0 \\
\hline & $4 \rrbracket$ & 39 & 0 & 0 & 2.56 & 2.56 & 10.26 & 15.38 & 66.67 & 25.64 & 69.23 & 17.95 & 33.33 & 5.13 & 12.82 & 30.77 & 7.69 \\
\hline & 50 & 48 & 0 & 0 & 0 & 0 & 0 & 10.42 & 64.58 & 54.17 & 58.33 & 20.83 & 25.00 & 25.00 & 14.58 & 20.83 & 6.25 \\
\hline & 60 & 16 & 6.25 & 12.50 & 6.25 & 6.25 & 0 & 6.25 & 43.75 & 37.50 & 62.50 & 25.00 & 31.25 & 25.00 & 18.75 & 18.75 & 0 \\
\hline \multicolumn{2}{|c|}{ Subtotal } & 151 & 2.65 & 2.65 & 1.99 & 1.99 & 3.31 & 11.26 & 59.60 & 40.40 & 64.90 & 22.52 & 29.80 & 17.88 & 12.58 & 23.84 & 3.97 \\
\hline \multirow[t]{4}{*}{ Girls } & $3 \rrbracket$ & 44 & 2.27 & 2.27 & 9.09 & 2.27 & 2.27 & 11.36 & 70.45 & 52.27 & 70.45 & 22.73 & 31.82 & 9.09 & 2.27 & 11.36 & 0 \\
\hline & $4 \rrbracket$ & 42 & 4.76 & 4.76 & 11.900 & 7.14 & 9.52 & 11.90 & 59.52 & 42.86 & 52.38 & 26.19 & 21.43 & 11.90 & 2.38 & 21.43 & 9.52 \\
\hline & $5 \square$ & 49 & 0 & 2.04 & 2.04 & 2.08 & 8.16 & 14.29 & 75.51 & 55.10 & 57.14 & 16.33 & 28.57 & 16.33 & 6.12 & 6.12 & 10.20 \\
\hline & 60 & 19 & 0 & 5.26 & 5.26 & 5.26 & 0 & 10.53 & 73.68 & 52.63 & 78.95 & 21.05 & 31.58 & 5.26 & 0 & 10.53 & 0 \\
\hline \multicolumn{2}{|c|}{ Subtotal } & 154 & 1.95 & 3.25 & 7.14 & 3.90 & 5.84 & 12.34 & 69.48 & 50.65 & 62.34 & 21.43 & 27.92 & 11.69 & 3.25 & 12.34 & 5.84 \\
\hline \multicolumn{2}{|c|}{ Average } & 305 & 2.30 & 2.95 & 4.59 & 2.95 & 4.59 & 11.80 & 64.59 & 45.57 & 63.61 & 21.97 & 28.85 & 14.75 & 8.20 & 18.03 & 4.92 \\
\hline
\end{tabular}

\section{Children's nutritional status}

The prevalence of underweight and wasting was $2.30 \%$ and $2.95 \%$, respectively, and there was no significant difference between boys and girls. The prevalence of stunting was $4.59 \%$ and was significantly lower in boys than in girls $\left(\chi^{2}=5.50, P=0.019\right)($ Table 1$)$. Although the nutritional status in the past and at present was good in $92.8 \%$ of children, the current nutritional status was poor in $1.31 \%$ of children. In the past, $3.61 \%$ of children had slightly poor nutritional status, and $2.29 \%$ were chronically malnourished (Table 2 ).

Table 2

Evaluation of nutritional status in preschool children

\begin{tabular}{|lllll|}
\hline \multirow{2}{*}{ Types $^{\text {a }}$} & Nutritional status & \multirow{2}{*}{ Percentage(\%) } \\
\cline { 2 - 4 } & Present & Past & \\
\hline All negative & Good & Good & 283 & 92.79 \\
\hline Stunting & Good & Bad & 11 & 3.61 \\
\hline Underweight & Slightly bad & Slightly good & 0 & 0.00 \\
\hline Wasting & Bad & Slightly good & 4 & 1.31 \\
\hline Underweight and stunting & Slightly bad & Bad & 2 & 0.65 \\
\hline Underweight and wasting & Bad & Bad & 4 & 1.31 \\
\hline All positive & Bad & Bad & 1 & 0.33 \\
\hline a According to the Z score values, stunting, wasting and underweight were defined when the values of HAZ, WHZ and WAZ were less than - 2 SD. & \\
\hline
\end{tabular}

The prevalence of overweight was $18.03 \%$ and was significantly higher in boys than in girls $\left(X^{2}=6.826, P=0.009\right)$. Notably, the overweight rate was the highest in children aged 4 years (Table 1$)$. The prevalence of obesity was $6.89 \%$ and was significantly higher in boys than in girls $\left(\chi^{2}=4.335, P=0.037\right)$. Overweight and obesity did not occur in children with low birth weights, and there was no significantly difference in the rate of overweight between children with high birth weights and those with normal birth weights (Fig. 1d).

\section{Levels of vitamin $A$, $E$ and $25-(\mathrm{OH})-\mathrm{D}_{3}$}

The average vitamin A content in serum was $0.54(0.11) \mu \mathrm{g} / \mathrm{ml}$. No vitamin A deficiency was observed in the children, but $7.54 \%$ of children were considered marginally vitamin A deficient. The average vitamin E content was $7.83(2.22) \mu \mathrm{g} / \mathrm{ml}$. Similarly, no vitamin E deficiency was observed in children. The content of 25-(OH)- $\mathrm{D}_{3}$ was $16.79(4.89) \mathrm{ng} / \mathrm{ml}$, and vitamin D-deficient, insufficient and sufficient children were $88.85 \%, 10.49 \%$ and $0.66 \%$, respectively.

The levels of the three vitamins tended to decrease gradually with increasing age (Fig. 2a). There was no significant difference between boys and girls. 25$(\mathrm{OH})-\mathrm{D}_{3}$ was positively correlated with $\mathrm{HCZ}(\mathrm{P}<0.05)$ (Table 3). Vitamin A was also positively associated with $25-(\mathrm{OH})-\mathrm{D}_{3}(\mathrm{P}<0.05)(\mathrm{Fig} .2 \mathrm{~b})$. 
Table 3

The correlation between vitamin nutritional status and Z scores among preschool children

\begin{tabular}{|lllllll|}
\hline Z scores & \multicolumn{3}{c}{ Vitamin A } & \multicolumn{5}{c|}{ Vitamin E } & 25-(OH)- $\mathbf{D}_{\mathbf{3}}$ \\
\cline { 2 - 7 } & $\mathbf{r}$ & $\mathbf{P}$ & $\mathbf{r}$ & $\mathbf{P}$ & $\mathbf{r}$ & $\mathbf{P}$ \\
\hline WHZ & -0.042 & 0.460 & -0.030 & 0.607 & -0.044 & 0.554 \\
WAZ & -0.076 & 0.183 & -0.018 & 0.758 & -0.069 & 0.354 \\
\hline HAZ & -0.020 & 0.730 & -0.065 & 0.261 & 0.105 & 0.153 \\
\hline HCZ & -0.104 & 0.069 & -0.039 & 0.501 & 0.160 & 0.029 \\
\hline WHZ, weight for height. WAZ, weight for age. HAZ, height for age. HCZ, head circumference for age. \\
\hline
\end{tabular}

\section{Discussion}

The present study evaluated the growth and nutritional status of preschool children in the most northern and coldest parts of China. We found the coexistence of stunting and overweight/obesity, the so-called "double burden" of malnutrition, in the region. We also found that stunting mainly occurred in girls, while boys had a higher risk of obesity. Moreover, vitamin $25-(\mathrm{OH})-\mathrm{D}_{3}$ deficiency was common $(88.85 \%)$, which should draw much attention for nutritional interventions.

In this study, the physical development of boys and girls was in accordance with the general trend of childhood growth; that is, the height, weight and head circumference gradually increased with age, and the total development levels were better in boys than in girls. Compared with China's growth reference, the height was lower, but the weight and head circumference were similar among preschool children in Daxing'anling[8]. This might be related to the local cold climate. The winter is long and daylight is short, and the children's outdoor exercise was relatively low. Our results were consistent with the Northern Finland survey[19]. However, the physical development levels were close to or met the WHO standard[22]. Due to the development of the economy and the improvement of people's living standards, the physical development of preschool children in this area was relatively good.

Growth and development levels were between - 1 SD and + 1 SD, similar to those of children in Jordan[28]. WAZ is sensitive to recent nutritional changes in children. It was found that WAZ was relatively low among children aged 3 to 4 years. The main reason may be that children aged 3 to 4 years may be accustomed to a children's diet, and as they gradually enter the adult's diet model, the composition or intake of food changes. If children do not adapt to these changes, growth will be affected. WHZ is a sensitive indicator that reflects acute nutritional status. Weight for height Z scores were more than - 1 SD among $92.55 \%$ of children, indicating that the children were slightly overweight, although the nutritional status of children was generally good. HAZ mainly reflects the long-term and chronic nutritional status of the past. In total, $83.28 \%$ of children had a HAZ greater than - 1 SD, which is significantly higher than children in Central Brazil[29]. Head circumference growth was accompanied by an increase in brain capacity. HCZ can reflect the brain development of children. In this study, the levels of head circumference were normal in most children.

Compared with other areas in China, our results showed that the rates of underweight, stunting and wasting in Daxing'anling were lower than those of Wuzhong, a city in Northwest China[30]; the rates of overweight and obesity were higher than those of Xiamen, a city in Southeast China[31]. Similarly, compared with other developing countries, the rates of undernutrition were lower than those of Indonesia[32]. The prevalence of overweight was higher than that of Brazil[33], and the prevalence of obesity was also higher than that of Ethiopia[34]. However, because of the cold temperature in Daxing'anling, the intake of meat and other fatty foods is relatively high, while outdoor exercise is less than in warm places. Therefore, cold temperatures might be an important reason for the high rate of obesity in preschool children. In our study, the prevalence of obesity was higher in boys than in girls, consistent with the Tianjin survey[35].

It was shown that children with high birth weights might have a higher risk of obesity, although there were no significantly difference in the rates of obesity and overweight between children with high birth weights and with normal birth weights. Although the birth weight reflected the nutritional status of the foetus in the uterus, it could also indicate a strong ability to absorb nutrients. More nutrients and energy are consumed after birth, eventually leading to overnutrition. The problem of overnutrition in children is especially prominent in cold areas of China and is related to dietary habits, a short outdoor time and a long resting time[36]. Consequently, it is essential to strengthen nutritional interventions, focusing on the importance of a balanced diet, children's behaviour and outdoor exercise. Interventions could contribute to improving parents' knowledge levels and health awareness in various ways and help children develop good habits. Finally, it could not only effectively promote the growth and development of children but also improve their nutritional status.

Our study suggested that the levels of vitamins among preschool children were not good. Further study is needed to investigate the risk factors of vitamin $A$ and D deficiency. The rates of marginal vitamin A deficiency were lower than those of Chongqing, a mountain area in Southwest China[37]. However, vitamin D deficiency was serious in this area, and the prevalence of vitamin D deficiency was higher than that in Hangzhou, China[38], and Nepal[39]. The reason was probably that Hangzhou and Nepal are sunny areas and are much warmer than Daxing'anling. Therefore, children may stay outdoors longer. In our study, the levels of vitamin $\mathrm{D}$ in children aged 6 years had improved, which might be related to the increased resistance to diseases and outdoor activities. $25-(\mathrm{OH})-\mathrm{D}_{3}$ was positively associated with Vitamin A. Thus, parents should always take their children out in the sunshine.

\section{Strengths and Limitations}

In the current study, stratified cluster random sampling in four kindergartens according to the geographical location, climate, economic and cultural levels was used to reflect the average levels of the local region. In addition, the questionnaires from the preschool children's parents were completed via face-to-face 
interviews. Therefore, the data could be considered representative and credible. Although our study had a number of strengths, it was subject to several limitations. First, its cross-sectional design restricted the drawing of causal inferences. Additionally, the findings referred specifically to preschool children in Daxing'anling, the coldest region of China, and thus cannot be generalised to others. Finally, there was not enough background information to comprehensively compare the present health status of preschool children.

\section{Conclusions}

In summary, the extremely cold climate not only affected the growth and development but also the nutritional status of the local children. Therefore, we should strengthen the monitoring of nutrition and physical growth in preschool children and put forward effective preventive and health care strategies to ultimately promote their healthy growth.

\section{Abbreviations}

Not applicable

\section{Declarations}

\section{Ethics approval and consent to participate}

Ethics of human subject participation: This study was conducted according to the guidelines of the Declaration of Helsinki, and all procedures involving human subjects were approved by the Harbin Medical University Ethics Committee. Written informed consent was obtained from the children's parents/guardians.

\section{Consent to publish}

All authors read and approved the final manuscript.

\section{Availability of data and materials}

The questionnaire used in your study was developed for this study.

\section{Competing interests}

The authors declare no conflict of interest.

\section{Funding}

This research did not receive any specific grant from funding agencies in the public, commercial, or not-for-profit sectors.

\section{Authors' Contributions}

Y.C., X.C. and Y.Z. designed the study. N.W. and X.C. were the main investigators of the research. N.W., M.Y.S. and L.Y.M. performed the statistical analysis. Y.C. L.W. and Y.Z. drafted and revised the manuscript.

\section{Acknowledgements}

Not applicable.

\section{References}

1. Black RE, Allen LH, Bhutta ZA, Caulfield LE, de Onis M, Ezzati M, et al. Maternal and child undernutrition: global and regional exposures and health consequences. Lancet. 2008; 371: 243-260.

2. Black RE, Victora CG, Walker SP, Bhutta ZA, Christian P, de Onis M, et al. Maternal and child undernutrition and overweight in low-income and middleincome countries. Lancet. 2013; 382: 427-451.

3. Bhutta ZA, Das JK, Rizvi A, Gaffey MF, Walker N, Horton S, et al. Evidence-based interventions for improvement of maternal and child nutrition: what can be done and at what cost? Lancet. 2013; 382: 452-477.

4. Sen P, Bharati S, Som S, Pal M, Bharati P. Growth and nutritional status of preschool children in India: A study of two recent time periods. Food Nutr Bull. 2011; 32: 84-93.

5. Lumeng JC, Kaciroti N, Frisvold DE. Changes in body mass index z score over the course of the academic year among children attending Head Start. Acad Pediatr. 2010; 10: 179-186.

6. Gubbels JS1, Kremers SP, Goldbohm RA, Stafleu A, Thijs C. Energy balance-related behavioural patterns in 5-year-old children and the longitudinal association with weight status development in early childhood. Public Health Nutr. 2012; 15: 1402-1410.

7. Corvalán C, Uauy R, Mericq V. Obesity is positively associated with dehydroepiandrosterone sulfate concentrations at $7 \mathrm{y}$ in Chilean children of normal birth weight. Am J Clin Nutr. 2013; 97: 318-325. 
8. Coordinating Study Group of Nine Cities on Physical Growth and Development of Children, Capital Institute of Pediatrics. A national survey on growth of children under 7 years of age in nine cities of China, 2005. Zhonghua Er Ke Za Zhi. 2007; 45: 609-614.

9. Yang Z, Duan Y, Ma G, Yang X, Yin S. Comparison of the China growth charts with the WHO growth standards in assessing malnutrition of children. BMJ Open. 2015; 5: e006107.

10. Kherkheulidze M1, Nemsadze K, Kavlashvili N, Kandelaki E, Adamia N. The parameters of physical growth in 5-6 years old children in Tbilisi. Georgian Med News. 2010; 178: 52-56.

11. Nouri Saeidlou S, Babaei F, Ayremlou P. Malnutrition, overweight, and obesity among urban and rural children in north of west Azerbijan, Iran. J Obes. 2014; 2014: 541213.

12. De Onis M, Blössner M, Borghi E. Global prevalence and trends of overweight and obesity among preschool children. Am J Clin Nutr. 2010; $92: 1257-1264$.

13. Jiang XX, Hardy LL, Baur LA, Ding D, Wang L, Shi HJ. High prevalence of overweight and obesity among inner city Chinese children in Shanghai, 2011. Ann Hum Biol. 2014; 41: 469- 472.

14. Ji CY, Cheng TO. Epidemic increase in overweight and obesity in Chinese children from 1985 to 2005. Int J Cardiol. 2009; $132: 1-10$.

15. Zong XN, Li H. Secular trends in prevalence and risk factors of obesity in infants and preschool children in 9 Chinese cities, 1986-2006. PLoS One. 2012; 7: e46942.

16. Song Y, Ma J, Wang HJ, Wang Z, Hu P, Zhang B, et al. Secular trends of obesity prevalence in Chinese children from 1985 to 2010 : Urban-rural disparity. Obesity (Silver Spring). 2015; 23: 448-453.

17. National Health and Family Planning Commission of the People's Republic of China. The Situation of Chinese Residents' Nutrition and Chronic Disease in 2015. Beijing, China: People's Medical Publishing House Press; 2015.

18. Xu Z, Etzel RA, Su H, Huang C, Guo Y, Tong S. Impact of ambient temperature on children's health: a systematic review. Environ Res. 2012; 117:120-131.

19. Rasi H, Kuivila H, Pölkki T, Bloigu R, Rintamäki H, Tourula M. A descriptive quantitative study of 7-and 8-year-old children's outdoor recreation, cold exposure and symptoms in winter in Northern Finland. Int J Circumpolar Health. 2017; 76: 1298883.

20. Frank DA, Roos N, Meyers A, Napoleone M, Peterson K, Cather A, et al. Seasonal variation in weight-for-age in a pediatric emergency room. Public Health Rep. 1996; 111: 366-371.

21. World Medical Association. World Medical Association Declaration of Helsinki: ethical principles for medical research involving human subjects. JAMA. 2013; 310: 2191- 2194.

22. World Health Organization. Child growth standards. Geneva:WHO. 2006.

23. Crookston BT, Schott W, Cueto S, Dearden KA, Engle P, Georgiadis A, et al. Postinfancy growth, schooling, and cognitive achievement: Young Lives. Am J Clin Nutr. 2013; 98: 1555-1563.

24. Holick MF, Binkley NC, Bischoff-Ferrari HA, Gordon CM, Hanley DA, Heaney RP, et al. Evaluation, treatment, and prevention of vitamin D deficiency: an Endocrine Society clinical practice guideline. J Clin Endocrinol Metab. 2011; 96: 1911-1930.

25. Pramyothin P, Holick MF. Vitamin D supplementation: guidelines and evidence for subclinical deficiency. Curr Opin Gastroenterol. $2012 ; 28$ : $139-150$.

26. Holick MF, Binkley NC, Bischoff-Ferrari HA, Gordon CM, Hanley DA, Heaney RP, et al. Guideliness for preventing and treating vitamin D deficiency and insufficiency revisited. J Clin Endocrinol Metab. 2012; 97: 1153-1158.

27. Holick MF. Vitamin D deficiency. N Engl J Med. 2007; 357: 266-281.

28. Hawamdeh ZM, Ibrahim Al. Physical growth and nutritional status of Jordanian preschool-aged children. Minerva Pediatr. 2008; 60: $1375-1383$.

29. Ferreira AA, Welch JR, Santos RV, Gugelmin SA, Coimbra CE Jr. Nutritional status and growth of indigenous Xavante children, Central Brazil. Nutr J. 2012; 11: 3 .

30. Li XQ, Zhang WS, Liu Y, Wu GF, Yan XF, Mao XM. Growth status of children under 7 years in Wuzhong City, Ningxia Hui Autonomous Region, China and its influential factors. Zhongguo Dang Dai Er Ke Za Zhi. 2013; 15: 289-293.

31. Chen J, Chen W, Zeng G, Li G. Secular Trends in Growth and Nutritional Outcomes of Children under Five Years Old in Xiamen, China. Int J Environ Res Public Health. 2016; 13(11): 1104.

32. Nazri C,Yamazaki C,Kameo S, Herawati DMD, Sekarwana N, Raksanagara A, et al. Factors influencing mother's participation in Posyandu for improving nutritional status of children under-five in Aceh Utara district, Aceh province, Indonesia. BMC Public Health. 2016; 16: 69.

33. Menezes RC,Lira PI,Oliveira JS, Leal VS, Santana SC, Andrade SL, et al. Prevalence and determinants of overweight in preschool children. J Pediatr(Rio J). 2011; 87: 231-237.

34. Gebremedhin S. Prevalence and differentials of overweight and obesity in preschool children in Sub-Saharan Africa. BMJ Open. $2015 ; 5$ : e009005.

35. Xiao Y, Qiao Y, Pan L, Liu J, Zhang T, Li N, et al. Trends in the Prevalence of Overweight and Obesity among Chinese Preschool Children from 2006 to 2014. PLoS One. 2015; 10: e0134466.

36. De Coen V, De Bourdeaudhuij I, Verbestel V, Maes L, Vereecken C. Risk factors for childhood overweight:a 30-month longitudinal study of 3 to 6-year-old children. Public Health Nutr. 2014; 17: 1993-2000.

37. Chen K, Zhang X, Li TY, Chen L, Qu P, Liu YX. Co-assessment of iron, vitamin A and growth status to investigate anemia in preschool children in suburb Chongqing, China. World J Pediatr. 2009; 5: 275-281.

38. Zhu Z, Zhan J, Shao J, Chen W, Chen L, Li W, et al. High prevalence of vitamin D deficiency among children aged 1 month to 16 years in Hangzhou, China. BMC Public Health. 2012; 12: 126.

39. Avagyan D, Neupane SP, Gundersen TE, Madar AA. Vitamin D status in preschool children in rural Nepal. Public Health Nutr. $2016 ; 19: 470-476$. 
Figures
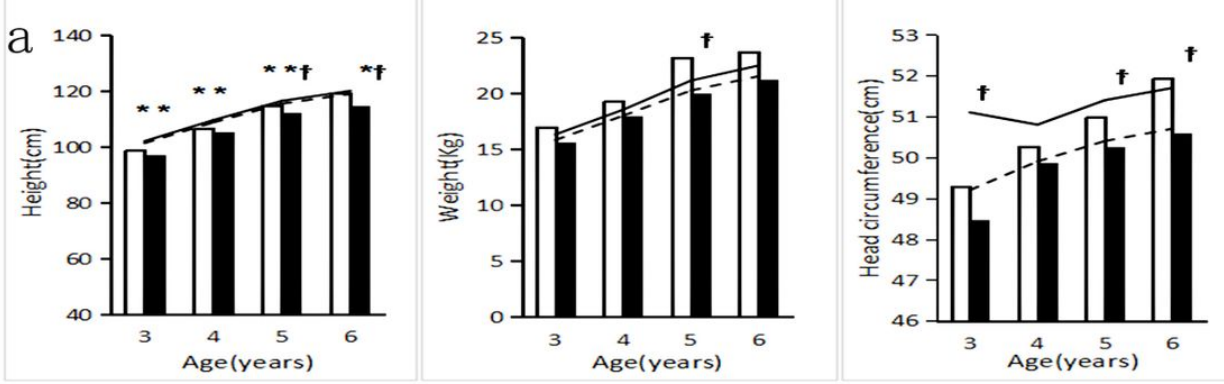

b

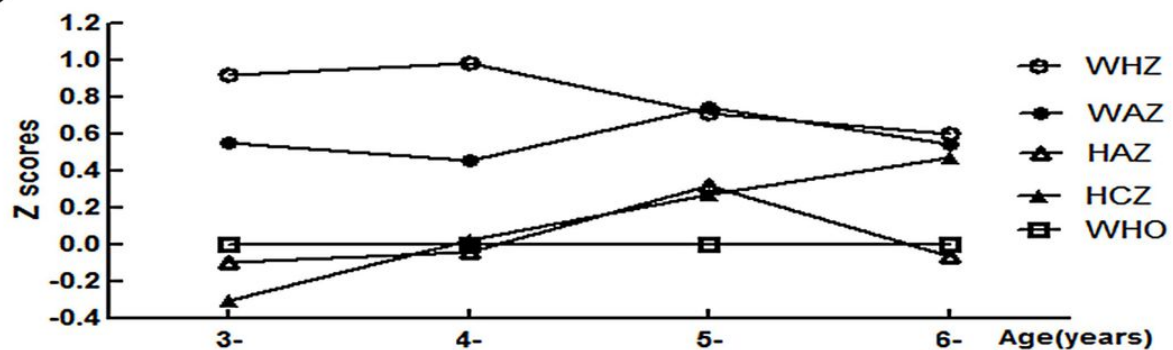

C

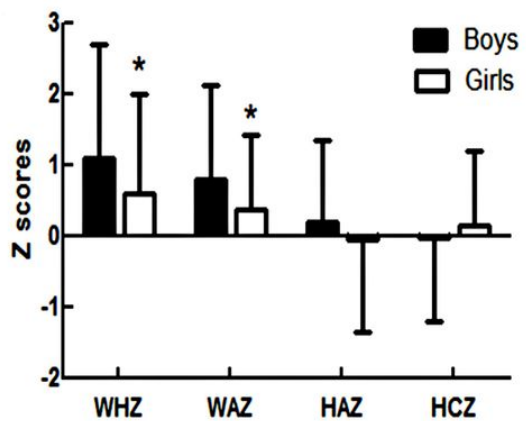

d

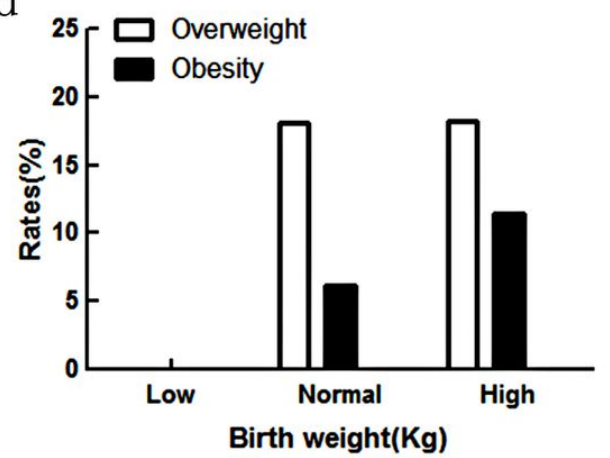

Figure 1

(a) Physical measurement children aged 3-6 years. (Local boys; Local girls; Reference boys; Reference girls), reference boys and girls were from cities in China in 2005. *Compared with the same sex from cities in China $(P<0.05)$; +Compared with boys of the same age $(P<0.05)$. (b) The change trend of $z$-score with age in children aged 3-6 years.WHZ, weight for height. WAZ, weight for age. HAZ, height for age. HCZ, head circumference for age. WHO, World Health Organization. (c) Z-score differences between boys and girls of the same age group. *Compared with the $Z$ scores of boys of the same age ( $P<0.05)$. (d) The association of obesity and overweight rates with birth weight among children aged 3 to 6 years. 

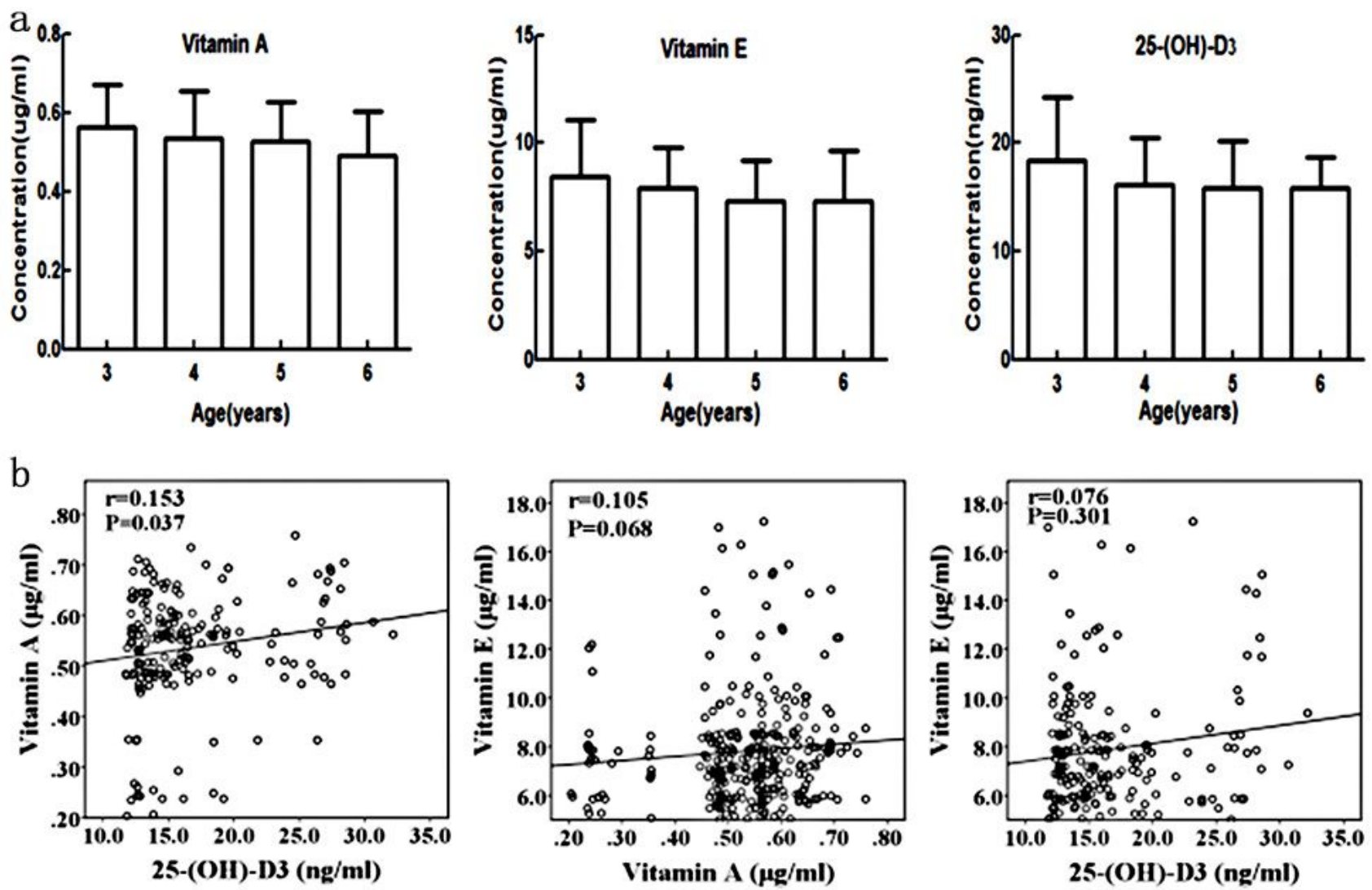

Figure 2

(a) Serum concentration of vitamin A, E and 25-(OH)-D3 in preschool children. (b) Correlation of serum vitamin nutritional status among preschool children. 